\title{
Molecular implementation of sequential and reversible logic through photochromic energy transfer switching
}

Patricia Remón, ${ }^{[\mathrm{a}]}$ Martin Hammarson, ${ }^{[\mathrm{b}]}$ Shiming Li, ${ }^{[\mathrm{b}]}$ Axel Kahnt, ${ }^{[\mathrm{b}]}$ Uwe Pischel, $*{ }^{[\mathrm{a}]}$ and Joakim Andréasson* ${ }^{[b]}$

In memoriam of Rafael Suau

[a] P. Remón, Prof. Dr. U. Pischel

Center for Research in Sustainable Chemistry (CIQSO)

University of Huelva

Campus de El Carmen, s/n, E-21071 Huelva (Spain)

Fax: (+34)959-219983

E-mail: uwe.pischel@diq.uhu.es

[b] M. Hammarson, Dr. A. Kahnt, Dr. S. Li, Prof. Dr. J. Andréasson

Department of Chemical and Biological Engineering

Physical Chemistry, Chalmers University of Technology

41296 Göteborg (Sweden)

Fax: (+46)31-772 3858

E-mail: a-son@chalmers.se

Supporting information for this article is available on the WWW under http://www.chemeurj.org/ or from the author. 


\begin{abstract}
Photochromic spiropyrans modified with fluorophores were investigated as molecular platforms for the realization of fluorescence switching through modulation of energy transfer. The dyads have been designed such that energy transfer is only observed for the open forms (merocyanine and protonated merocyanine) of the photochrome, while the closed spiropyran is inactive as energy acceptor. This was possible by intentionally choosing fluorophores (4-amino-1,8-naphthalimide, dansyl, and perylene), which lead to a zero spectral overlap with the spiro form and considerable overlap for the merocyanine forms. Based on the Förster theory, energy transfer is predicted to be highly efficient and in some cases of unit efficiency. The combined switching by photonic (light of $\lambda>530 \mathrm{~nm}$ ) and chemical (base) inputs enabled the realization of a sequential logic device, which is the basic element of a keypad lock. Furthermore, in combination with an anthracene-based acidochromic fluorescence switch, a reversible logic device was designed. The latter enables the unambiguous coding of different input combinations through multicolour fluorescence signalling. All devices can be conveniently reset to their initial state and repeatedly cycled.
\end{abstract}




\section{Introduction}

The idea of using molecular systems for mimicking binary information processing has attracted considerable interest in recent years. ${ }^{[1-4]}$ On the one hand, such molecular entities could be imagined as building blocks for molecular computers. However, in practice, problems like the concatenation of several logic devices create the bottleneck for such applications. ${ }^{[4]}$ On the other hand, the utility of molecular logic is not restricted to computing, ${ }^{[5]}$ but has for example emergent interest for smart materials, ${ }^{[6]}$ pro-drug activation, ${ }^{[7,8]}$ labelling of micro-objects, ${ }^{[9]}$ multiparameter sensing ${ }^{[10]}$ and molecular diagnostic tools. ${ }^{[11,12]}$

Many of the numerous molecular logic devices, which have been reported so far, use chemical signals as inputs and fluorescence signals as conveniently readable outputs. ${ }^{[1-3]}$ The photophysical basis for these systems is often constituted by wellunderstood energy transfer and electron transfer processes. ${ }^{[13]}$ This facilitates the rational design of such switches and enables the effective control of the fluorescence output. The same excited state pathways were found to be modulated by the interaction of fluorophores with photochromic molecules in appropriately designed dyads, leading to novel photonic switches. ${ }^{[14,15]}$ Photochromes themselves can be understood as bistable or sometimes multistable systems, where the involved states show considerably different properties like UV/vis absorption and redox potentials. One of the most notorious applications for information processing with photochromes is their exploitation as molecular memories. ${ }^{[16-23]}$ Noteworthy, even more complex logic operations such as those of multiplexers, ${ }^{[24]}$ demultiplexers, ${ }^{[25]}$ encoders, decoders, ${ }^{[26]}$ half-adders, ${ }^{[27,28]}$ and keypad locks, ${ }^{[2]}$ have been devised by combining the action of several photochromes. This opened a strategy for the design of all-photonic molecular logic devices, which use exclusively optical input and output signals.

One of the most popular classes of photochromic switches are spiropyrans such as 1-SP (Scheme 1). For these compounds three different states are observed: SP (spiro form), $\mathrm{ME}$ (merocyanine form), and $\mathrm{MEH}^{+}$(protonated merocyanine form). Due to the pronounced differences in the absorption spectra of these states, energy transfer switching has been used to control the fluorescence intensity of an attached fluorescent unit in spiropyran-based supramolecular constructs (dyads etc.). This has been accomplished in fluid solution, ${ }^{[30]}$ in polymers, ${ }^{[31]}$ on nanoparticles, ${ }^{[32]}$ and in live cells. ${ }^{[33]}$ As shown in Scheme 1, spiropyran photochromes combine the use of photonic and chemical input signals. In the present work, the covalent linking of a nitrospiropyran with carefully chosen fluorophores (dansyl, 4-amino-1,8-naphthalimide, and perylene) enabled fluorescence switching through the modulation of energy transfer processes by action of chemical and photonic inputs. The rational design and comprehensive interpretation of the switching behaviour was used herein for the realization of a fluorescent sequential logic device, which is the basic function of a molecular keypad lock. ${ }^{[29,34-38]}$ In combination with an anthracene fluorescence switch also a logically reversible gate was devised. ${ }^{[39,40]}$

\section{Results and Discussion}

Synthesis of the spiropyran-spacer-fluorophore dyads (2-SP, 3-SP, 4-SP) and model compounds. The complete synthesis sequence for the dyads is shown in Scheme 2a. The preparation of 1-SP was accomplished by starting with the commercial 2,3,3trimethylindolenine and following a three step procedure, which was slightly modified with respect to the literature (see Supporting Information). ${ }^{[41,42]}$ Alkylation of the indolenine with methyl 4-bromobutyrate gave the corresponding indolinium salt. In the 
second step this salt was reacted with 5-nitrosalicylaldehyde to yield the nitrospiropyran in its methyl ester form. The ester was finally treated with sodium hydroxide in tetrahydrofuran, followed by acidification with citric acid to yield 1-SP. This compound was then further functionalized with the corresponding fluorophores through formation of an amide. The best yields were obtained by previous acid activation with the NHS ester method (see Supporting Information). Reaction of the NHS ester with the corresponding fluorophore amine derivatives yielded the target dyads 2-SP, 3-SP, and 4-SP (yields of 54\%, 57\%, and 68\%, respectively). The fluorophore amine derivatives were prepared as described in the Supporting Information. The fluorophore model compounds (2-M, 3-M, and 4-M) were obtained by direct acetylation of the amines with acetyl chloride or acetic anhydride (Scheme $2 b$ ).

Photochromic behaviour of model spiropyran 1-SP. Compound 1-SP can be considered as a model spiropyran in our study, because it resembles the photochrome part of all herein investigated dyads. As shown in Scheme 1, irradiation of the SP form $\left(\lambda_{\max }=341 \mathrm{~nm}, \varepsilon=7500 \mathrm{M}^{-1} \mathrm{~cm}^{-1}\right)$ with UV light $(\lambda=302 \mathrm{~nm}, 210 \mathrm{~s})$ leads to ring opening and the generation of the ME form (1-ME). This one is characterized by a substantially red-shifted absorption band at $\lambda_{\max }=565 \mathrm{~nm}\left(\varepsilon=36800 \mathrm{M}^{-1} \mathrm{~cm}^{-1}\right)$. The distribution between both forms in the photostationary state (PSS) was determined as $39 \%$ SP and $61 \%$ ME. 1-ME reverts thermally to 1-SP ( $\tau=6.1$ min at $20{ }^{\circ} \mathrm{C}$ ) or more rapidly with visible light irradiation. The time required for the photoinduced isomerization depends, of course, on the light intensity. Herein, irradiation at $\lambda>530$ $\mathrm{nm}$ with a light power density of $c a .18 \mathrm{~mW} / \mathrm{cm}^{2}$ required $210 \mathrm{~s}$ exposure time for the ME to SP conversion. The addition of 1 equiv trifluoroacetic acid (TFA) to 1-ME generated the protonated $\mathrm{MEH}^{+}$form $\left(\mathbf{1}-\mathbf{M E H}^{+}\right)$, which was accompanied by a blue shift of the long-wavelength absorption maximum to $404 \mathrm{~nm}\left(\varepsilon=22700 \mathrm{M}^{-1} \mathrm{~cm}^{-1}\right)$. This process can be reversed by addition of 1 equiv of a strong phosphazene base $\left(\mathrm{P}_{2}-\mathrm{Et}\right)$. The corresponding absorption spectra of all three forms of $\mathbf{1}$ are shown in Figure 1. The open forms can be quantitatively transformed back to the closed SP form by irradiation with light of $\lambda>420 \mathrm{~nm}\left(\mathrm{ME}\right.$ and $\mathrm{MEH}^{+}$) or of $\lambda>530 \mathrm{~nm}$ for the selective conversion of ME.

Photophysical properties and photochromic switching of the dyads. All relevant spectral data of the dyads in their different forms (SP, ME, $\mathrm{MEH}^{+}$) and of the fluorophore models are compiled in Table 1. In Figure 2, the absorption spectra of the dyad 2-SP and the corresponding model compounds 1-SP and 2-M are compared. The combination of the spectra of the models yields the spectrum of the dyad, which rules out important ground state interactions. The same observations were made for the other two dyads (see Supporting Information). Noteworthy, the fluorophore emission of the dyads in their SP form is considerably quenched ( $c a .90 \%)$ in comparison to the emission of the model chromophores (Figure 2 for 2-M versus 2-SP). The underlying fluorescence quenching process is of dynamic nature, as has been verified by the observation of the same effect in fluorescence lifetime measurements. For example, for the 4-amino-1,8-naphthalimide fluorophore the quantum yield $\Phi_{\mathrm{f}}$ drops from 0.44 for 2 $\mathbf{M}$ to 0.056 for 2-SP and the lifetime $\tau_{\mathrm{f}}$ is $10.6 \mathrm{~ns}$ for 2-M and $1.40 \mathrm{~ns}$ for 2-SP (see Table 1). The mechanism for this fluorescence quenching is assumed to be photoinduced electron transfer (PET). Electronic energy transfer (EET) can be excluded, because the dyads were designed to give a zero spectral overlap integral between the fluorophore emission and the SP absorption spectrum (see below). In order to validate the hypothesis of PET, the driving force $\left(\Delta G_{\mathrm{PET}}\right)$ for the oxidative and reductive paths was calculated with the Rehm-Weller equation (equation 1). ${ }^{[30,43-46]}$ 
$\Delta G_{\mathrm{PET}}=E_{\mathrm{ox}}-E_{\mathrm{red}}-E^{*}+C$

In all cases, PET under oxidation of the fluorophore is exergonic and therefore thermodynamically feasible: $\Delta G_{\mathrm{PET}, \mathrm{ox}}=-0.31 \mathrm{eV},-0.91 \mathrm{eV},-0.76 \mathrm{eV}$ for $\mathbf{2 - S P}, \mathbf{3 - S P}$, and 4-SP, respectively (error $\pm 0.1 \mathrm{eV}$ ). The reductive PET was as well considered, but with exception of 2-SP $\left(\Delta G_{\mathrm{PET}, \text { red }}=-0.15 \pm 0.1 \mathrm{eV}\right)$ this path is endergonic $\left(\Delta G_{\mathrm{PET} \text {,red }}>\right.$ $0)$. Noteworthy, despite the exergonic thermodynamics in the case of 2-SP, the occurrence of reductive electron transfer is unlikely, because electron donors linked to the "imide side" of the chromophore do not quench the fluorescence of aminonaphthalimides. ${ }^{[47,48]}$ Hence, oxidative PET is a very likely possibility for the observed fluorescence quenching in the SP dyads. Assuming that PET is the only competitive fluorescence quenching process in the SP dyads, the quantum yield can be given with $\Phi_{\text {PET }} c a .0 .9$ (see equation 2 ).

$\Phi_{\mathrm{PET}}=1-\frac{\Phi_{\mathrm{f}, \mathrm{SP}}}{\Phi_{\mathrm{f}, \mathrm{M}}}$

As will be discussed below, the herein described dyads were designed to yield fluorescence switching in dependence on the state of the photochrome part. This idea is based on the control of very efficient EET (see below), being suppressed in the SP form of the dyads and activated for the other two forms $\left(\mathrm{ME}\right.$ and $\left.\mathrm{MEH}^{+}\right)$; i.e., an ON-OFF fluorescence switching upon photoinduced ring opening of the SP form. It should be stressed that in order to achieve the maximum ON-OFF discrimination, EET in the ME and $\mathrm{MEH}^{+}$forms of the dyads should be much more efficient compared to PET in the corresponding SP form. From the lifetimes in Table 1 it is clearly seen that this condition is fulfilled.

The fluorophores play the role of energy donors, while the photochrome part is the energy acceptor. According to the Förster theory of energy transfer, the efficiency $\left(\Phi_{\mathrm{EET}}\right)$ of this process depends crucially on the spectral overlap integral $J$ of the donor emission and the acceptor absorption (equations 3 and 4). With equation 3 the critical distance for energy transfer $\left(R_{0}\right)$ can be calculated (orientation factor $\kappa^{2}$ was assumed as $2 / 3$ ). This distance corresponds to a $50 \%$ efficiency of EET. For all dyads considerable $R_{0}$ values of 38-47 $\AA$ resulted for their ME form, whereas somewhat smaller values were determined for the $\mathrm{MEH}^{+}$form $\left(R_{0}=19-35 \AA\right)$. Importantly, and as intended, $R_{0}=$ $0 \AA$ applies for the SP form of the dyads, because the spectral overlap integral is zero. This means that EET in this photochromic state of the dyads does not occur. With the real distance between donor and acceptor the values for $\Phi_{\mathrm{EET}}$ can be calculated (equation 4). However, due to the conformational flexibility of the linker, the actual distance between donor and acceptor is expected to follow a distribution function. For this reason we assume an estimate value of the maximum distance, corresponding to the most extended conformation, with $R c a .15 \AA$. Most likely the real average distance is even smaller, as may be judged from the occurrence of PET in the SP form of the dyads (see above). This process would be not efficient (see Table 1) for a distance of $15 \AA$. In any case, this maximum distance is still significantly smaller than $R_{0}$ for both of the open forms. Thus, the lower limit values for EET efficiency show that for the ME form this process is expected to be quantitative $\left(\Phi_{\mathrm{EET}}=1\right)$ for all fluorophores, while for the protonated merocyanine form $\left(\mathrm{MEH}^{+}\right)$still considerably high values of $\Phi_{\mathrm{EET}} \geq 0.8$ should result. 


$$
\begin{aligned}
& R_{0}^{6}=\frac{9 \ln 10 \kappa^{2} \Phi_{\mathrm{D}}}{128 \pi^{5} n^{4} N_{\mathrm{A}}} J \quad \text { with } J=\int_{0}^{\infty} \frac{\mathrm{F}_{\mathrm{D}}(v) \varepsilon_{\mathrm{A}}(v) \mathrm{d} v}{v^{4}} \\
& \Phi_{\mathrm{EET}}=\frac{1}{1+\left(\frac{R}{R_{0}}\right)^{6}}
\end{aligned}
$$

The expected ON-OFF fluorescence switching upon conversion of the SP form to the ME form was experimentally verified for the irradiation of the dyads at $\lambda=302$ $\mathrm{nm}$. For example, the conversion $\mathbf{2 - S P} \rightarrow \mathbf{2 - M E}$ resulted in a fluorescence quenching of $40 \%$. This effect is even somewhat more pronounced for the dansyl- and perylenesubstituted spiropyrans (3-SP and 4-SP), where the emission reduces by about 50\% upon merocyanine formation. Clearly, the dynamic range of the fluorescence switching is dictated by the PSS distribution, which was found to be around 55/45 (\%SP/\%ME) for all three dyads. The similarity of the quenching and the ME contribution to the PSS is in line with the prediction of a very efficient energy transfer (see above). The comparison of the PSS distribution for the dyads and the spiropyran model compound 1-SP (\%SP/\%ME: 39/61) reveals that the photochromic ring opening process is somewhat affected in the dyads, which is possibly the result of photochrome excited state quenching by the fluorophores (e.g., through PET). The quantitative fluorescence quenching by EET in the dyads in their open forms $\left(\mathrm{ME}\right.$ and $\left.\mathrm{MEH}^{+}\right)$was also verified by fluorescence lifetime measurements (see Table 1). For the example of the dansylsubstituted photochrome (3-SP) a drastic reduction of the lifetime from 925 ps for the SP form to a few picoseconds (8-9 ps for the shortest lifetime component) for the ME and $\mathrm{MEH}^{+}$forms was observed (see Figure 3 ). The other two dyads yielded the same lifetime quenching trend (Table 1). In other words, each dyad molecule, which is converted from the SP to the open $\mathrm{ME} / \mathrm{MEH}^{+}$forms, shows quantitative fluorescence quenching.

With the complete characterization of the photochrome-modulated fluorescence switching at hand, we aimed at the realization of the following advanced logic functions: sequential molecular logic ${ }^{[49,50]}$ and reversible logic. ${ }^{[39,40]}$

Implementation of sequential logic by using chemical and photonic inputs. The outcome of a sequential logic operation is not only dependent on the correct combination of the inputs, but also on the order of their application. This implies the existence of a memory effect. Prominent examples for this type of logic switching are keypad locks and SR latches, ${ }^{[51]}$ for which a restricted number of molecular examples are known. Keypad locks are devices, which activate only if the right input combination is applied in a certain sequence. The so far reported molecular keypad locks rely, with one exception, ${ }^{[29]}$ on all-chemical input signals. ${ }^{[35-38]}$ This may bring along problems for the repeated use of the molecular system, which would require mechanisms for resetting and recycling.

As shown in Scheme 1, spiropyran photochromes do not only offer the possibility of light-induced switching, but their open forms can also be interconverted by protonation/deprotonation. Hence, three spectrally differentiated states (SP, ME, $\mathrm{MEH}^{+}$) can be observed for these photochromes. Effectively, a chemical (sensing) input and a remote-adressing photonic input are combined in a "hybrid approach" (neither allchemcial nor all-photonic). This can be used to devise comprehensive logic operations, ${ }^{[52-57]}$ beyond the bistable photoswitching of spiropyrans $(\mathrm{SP} \rightarrow \mathrm{ME}$ and vice versa). It should be noted here, that other classical photochromes, such as 
dithienylethenes or fulgimides, have only two differentiated states (closed and open form). Thus, in order to achieve complex logic functionality with these photochromes, several distinct units are commonly combined in a supermolecule conjugate. ${ }^{[24-26,28,29]}$

For the herein investigated spiropyran-fluorophore dyads, fluorescence constitutes a convenient output signal $\left(O_{1}\right)$. As initial state of our sequential logic device the $\mathrm{MEH}^{+}$form of the dyad was chosen. One input $\left(\mathrm{In}_{2}\right)$ is light of $\lambda>530 \mathrm{~nm}$, where the initial $\mathrm{MEH}^{+}$state has no absorption, but the $\mathrm{ME}$ form does absorb (see Figure 1). In order to generate the SP form, the $\mathrm{MEH}^{+}$form has to be converted to the ME form before irradiation with light of $\lambda>530 \mathrm{~nm}$ (see Scheme 3). This can be accomplished by deprotonation of the phenolic $\mathrm{OH}$ group with 1 equiv of $\mathrm{P}_{2}$-Et base, which is defined as input $I n_{1}$. Hence, it results that only one input order $\left(I n_{1}\right.$ followed by $\left.I n_{2}\right)$ yields the SP form and its corresponding high fluorescence output signal. The application of $I n_{2}$ and then $I n_{1}$ leaves the fluorescence output low. Because of the efficient EET fluorescence quenching in the $\mathrm{ME}$ and $\mathrm{MEH}^{+}$forms of the dyads, the binary input combinations 00, 01, and 10 produce also a low output signal (see Figure 4 for the example of 2-SP). In essence, this corresponds to a 2-input priority AND gate (2PAND). ${ }^{[29]}$ The switching can be repeated for at least five consecutive cycles with an acceptable dynamic OFF-ON range (Figure 5). According to the in Scheme 1 shown interconversions, resetting to the initial state $\left(\mathrm{MEH}^{+}\right.$form $)$is possible by application of UV light and addition of TFA $\left(\mathrm{SP} \rightarrow \mathrm{MEH}^{+}\right)$or sole addition of TFA $\left(\mathrm{ME} \rightarrow \mathrm{MEH}^{+}\right)$. Noteworthy, acid-base neutralizations are complete and fast reactions, producing just water and salts as byproducts. This is in contrast to some previously reported molecular keypad lock systems, ${ }^{[35,37,38]}$ where metal ion or anion inputs would have to be removed by addition of competitive ligands, which may potentially interfere in the repeated device operation.

Realization of reversible molecular logic by reading two compartmentalized logic gates. Reversible logic relies on the unambiguous mapping of input vectors to output vectors and vice versa. Hence, in this logic scheme each binary input combination leads to a unique output combination. A visibly different fluorescence output for each input combination is a promising approach for photonic coding of multiinput events. On the other hand, any basic two-input logic gate, having one output channel, is irreversible and information is lost upon processing the inputs. In order to achieve reversibility, a second output is needed which should enable exactly one nonrepeated output combination per input vector. Noteworthy, the term reversible logic is not to be confused with chemical reversibility, which is a precondition for recycling and resetting of a logic device (see for example Figure 5 for the above discussed case). In accordance with the necessity of two output channels, a PET-based anthracene fluorescence switch (5) and the spiropyran-fluorophore dyad 2-SP were used. Each of them shows fluorescence in spectrally well-distinguished regions and was operated in a separate cuvette. This compartmentalization approach was used earlier by others for the realization of logic networks. ${ }^{[54-56,58]}$

As initial states $\mathbf{5} \mathbf{H}^{+}$and $\mathbf{2 -} \mathbf{M E H}{ }^{+}$are chosen (Scheme 3 ) and the inputs are constituted by the addition of 1 equiv $\mathrm{P}_{2}$-Et base $\left(\operatorname{In}_{1}\right)$ and irradiation with light of $\lambda>$ $420 \mathrm{~nm}\left(I n_{3}\right)$. The outputs are defined as $O_{1}$ (aminonaphthalimide fluorescence) and $O_{2}$ (anthracene fluorescence); Figure 6. The irradiation of $\mathbf{2}-\mathbf{M E H} \mathbf{H}^{+}\left(\mathrm{In}_{3}\right)$ converts this dyad to its 2-SP form, which shows the highest fluorescence output. Deprotonation (via application of $I n_{1}$ ) yields 2-ME, where EET still keeps the fluorescence output $O_{1}$ low. Application of both inputs $\left(\mathrm{In}_{1}\right.$ and $\left.I n_{3}\right)$, regardless of their order, yields again the 2-SP form $\left(O_{1}\right.$ high). It is important to note that the change of the input irradiation wavelength to $\lambda>420 \mathrm{~nm}$, where both the $\mathrm{ME}$ form and the $\mathrm{MEH}^{+}$form are 
simultaneously irradiated, removes the above designed sequential feature and leads to combinational logic. Indeed, no sequential logic is required for the design of the reversible logic device. The behaviour of $\mathbf{2 - M E H ^ { + }}$ is conform with a TRANSFER gate (see upper logic circuit with $I n_{1}, I n_{3}, O_{1}$ in Scheme 4) ${ }^{[59]}$ On the other hand, the deprotonation through addition of base $\left(\operatorname{In}_{1}\right)$ to $\mathbf{5} \mathbf{H}^{+}$as initial state of the other switch activates PET from the appended amino function, yielding practically quantitative fluorescence quenching ( $>95 \%)$. The application of $I n_{3}$ has no consequence for the anthracene switch, which lacks significant absorption above $400 \mathrm{~nm}$. This is an important point, because the direct irradiation of anthracene may yield photoproducts, which is not desired in the present context of reversible logic. In this scenario $\mathbf{5} \mathbf{H}^{+}$acts as INVERTER gate with respect to $I n_{1}$ (or to a more complex circuit with respect to both inputs $I n_{1}$ and $I n_{3}$; see lower part of the circuit in Scheme 4). The combination of both switches in one truth table (Table 2) shows that each input combination corresponds exactly to one unique output combination. The chemical processes (lightinduced or acid-base triggered) for 2-SP/2-MEH ${ }^{+}$are reminiscent of the above shown data (Figure 5, the selective irradiation of ME at $\lambda>530 \mathrm{~nm}$ is substituted by light of $\lambda$ $>420 \mathrm{~nm}$, which isomerizes both the $\mathrm{MEH}^{+}$and the $\mathrm{ME}$ form to the SP form). Hence, the recycling and reset capability of the system is identical. The recycling of the anthracene switch $\mathbf{5}$ for various alternating additions of acid and base is possible as well (see Supporting Information).

\section{Conclusion}

The emission of carefully selected fluorophores (aminonaphthalimide, dansyl, and perylene) appended to a spiropyran can be controlled by switching of electronic energy transfer. The dyads have been designed to yield large spectral overlap between the fluorophore emission and the absorption of the open merocyanine forms of the photochrome, while the closed spiropyran form has a zero overlap integral. The dynamic range of the switching is dependent on the photostationary state distribution of the closed spiropyran and the open merocyanine, which in all cases reached an approximate ratio of 55/45 (\%SP/\%ME). This corresponds to an OFF-ON switching factor of $c a$. 2. The fluorescence modulation can be used to design a sequential molecular logic device, working as a two-input priority AND gate (2-PAND) and in conjunction with an acidochromic anthracene PET switch a logically reversible gate resulted. These two comprehensive logic functions have been realized with only few examples so far. The herein chosen hybrid approach (combination of chemical and photonic signals) is a promising strategy for achieving high levels of logic functionality. The coinciding photonic nature of the output and one input allows in principle concatenation. Finally, from a conceptual point of view, the chemical input serves as an example of a sensing input, while the photonic input opens the possibility of remotecontrolling the device.

\section{Experimental Section}

Irradiations. The $\lambda>420 \mathrm{~nm}$ and $\lambda>530 \mathrm{~nm}$ light were generated by a $150 \mathrm{~W}$ Xe lamp together with longpass glass filters $(\lambda$ cut-on $=420 \mathrm{~nm}$ and $530 \mathrm{~nm})$. The resulting light power densities on the samples were $\sim 30 \mathrm{~mW} / \mathrm{cm}^{2}$ and $\sim 18 \mathrm{~mW} / \mathrm{cm}^{2}$, respectively. The $302 \mathrm{~nm}$ UV light was generated by a UVP hand-held UV lamp (Model UVM-57, $1.5 \mathrm{~mW} / \mathrm{cm}^{2}$ power density). The irradiation time used for the photo-isomerizations was $210 \mathrm{~s}$ in all cases. 
Photophysical measurements. All measurements were performed in air-equilibrated acetonitrile solutions at room temperature. The UV/vis absorption spectra were recorded with a UV-1603 spectrophotometer from Shimadzu or a CARY 5000 UV-vis-NIR spectrophotometer. The fluorescence spectra were recorded with a Cary Eclipse fluorimeter from Varian. The fluorescence quantum yields were determined with quinine sulfate $\left(\Phi_{\mathrm{f}}=0.55 \text { in } 0.05 \mathrm{M} \mathrm{H}_{2} \mathrm{SO}_{4}\right)^{[60]}$ as standard and corrected for differences of the refractive index of the reference and sample solvents. The quantum yield of dansyl fluorescence in dyad 3-SP is corrected for the absorbance of the spiropyran at the excitation wavelength $(341 \mathrm{~nm})$.

The absorption spectra shown in Figure 1 were recorded on a sample where virtually $100 \%$ was converted to the respective form. The experimental protocol has been previously described in the literature. ${ }^{[61]}$

The fluorescence lifetimes of 2-M, 3-M, 4-M and the corresponding lifetimes of 2-SP, 3-SP, and 4-SP were measured using pulsed laser diodes at $377 \mathrm{~nm}$ or $405 \mathrm{~nm}$ (PicoQuant) with $10 \mathrm{MHz}$ repetition rate as the excitation source. The emitted photons were recorded at $505 \mathrm{~nm}$ under magic angle conditions and were detected using a thermoelectrically cooled microchannel plate photomultiplier tube (MCP-PMT R3809U-50; Hamamatsu). The fluorescence signals were recorded until 10000 counts were obtained in the top channel.

The lifetimes of the ME and $\mathrm{MEH}^{+}$forms of the dyads (2-ME, 3-ME, 4-ME, 2-MEH ${ }^{+}$,

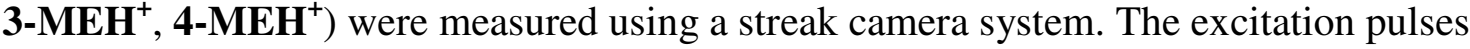
were provided by a Tsunami Ti:sapphire laser (Spectra-Physics) that was pumped by a Millennia Pro X laser (Spectra-Physics). The Tsunami laser output was tuned to $796 \mathrm{~nm}$ and subsequently frequency-doubled to $398 \mathrm{~nm}$. The photons emitted from the samples were pathing a spectrograph (Acton SP2300 - Princeton Instruments) and were registered with a streak camera (C5680-Hamamatsu) with a synchroscan unit (M5675 Hamamatsu). Every single frame was measured and stored individually and the time resolved fluorescence spectra were obtained after jitter correction. From these timeresolved fluorescence spectra, the fluorescence time profiles were extracted and fitted to bi-exponential expressions, including the instrument response function. The samples of the $\mathrm{ME}$ and the $\mathrm{MEH}^{+}$forms of the dyads were repeatedly refreshed with 1 min doses of $302 \mathrm{~nm}$ light during the time-resolved fluorescence measurements.

Example procedure for the synthesis of the fluorophore-spiropyran dyads (2-SP). A solution of the succinimidyl ester of 1-SP $(50 \mathrm{mg}, 0.1 \mathrm{mmol})$ and $N$-(2-aminoethyl)4-amino-1,8-naphthalimide (26 mg, $0.1 \mathrm{mmol})$ in tetrahydrofuran/dichloromethane $(2 / 3$, $8 \mathrm{~mL}$ ) and $N, N$-dimethylformamide $(4 \mathrm{~mL})$ was stirred at room temperature for $2.5 \mathrm{~h}$. The resulting mixture was diluted with dichloromethane and washed with brine and water. The organic phase was dried over $\mathrm{Na}_{2} \mathrm{SO}_{4}$. Removal of the solvent with a rotary evaporator yielded the crude product, which was purified by flash chromatography $\left(\mathrm{SiO}_{2}\right)$ with a mixture of dichloromethane/methanol (95/5) as eluent. $34 \mathrm{mg}$ (54\% yield) of 2-SP were obtained.

${ }^{1} \mathrm{H}$ NMR $\left(400 \mathrm{MHz}, \mathrm{CDCl}_{3}, 25^{\circ} \mathrm{C}\right) \delta=8.57(\mathrm{dd}, J=7.2,0.8 \mathrm{~Hz}, 1 \mathrm{H} ; \mathrm{Ar}-\mathrm{H}), 8.37(\mathrm{~d}, J$ $=8.4 \mathrm{~Hz}, 1 \mathrm{H}$; Ar-H), $8.10(\mathrm{dd}, J=8.4,0.8 \mathrm{~Hz}, 1 \mathrm{H}$; Ar-H), $7.95(\mathrm{dd}, J=8.8,2.4 \mathrm{~Hz}, 1 \mathrm{H}$; Ar-H), $7.90(\mathrm{~d}, J=2.4 \mathrm{~Hz}, 1 \mathrm{H} ; \mathrm{Ar}-\mathrm{H}), 7.63(\mathrm{t}, J=8.0 \mathrm{~Hz}, 1 \mathrm{H} ; \mathrm{Ar}-\mathrm{H}), 7.12$ (dt, $J=8.0$, $1.2 \mathrm{~Hz}, 1 \mathrm{H} ; \mathrm{Ar}-\mathrm{H}), 7.03$ (dd, $J=7.6,0.8 \mathrm{~Hz}, 1 \mathrm{H} ; \mathrm{Ar}-\mathrm{H}), 6.88-6.76$ (m, 3H; Ar-H), 6.66 $(\mathrm{d}, J=8.8 \mathrm{~Hz}, 1 \mathrm{H} ; \mathrm{Ar}-\mathrm{H}), 5.58(\mathrm{~d}, J=7.6 \mathrm{~Hz}, 1 \mathrm{H} ; \mathrm{Ar}-\mathrm{H}), 6.34(\mathrm{~m}, 1 \mathrm{H} ; \mathrm{NH}), 5.80(\mathrm{~d}, J$ $=10.4 \mathrm{~Hz}, 1 \mathrm{H}$; vinyl-H), 5.01 (br. s, $\left.2 \mathrm{H} ; \mathrm{NH}_{2}\right), 4.40-4.32\left(\mathrm{~m}, 2 \mathrm{H} ; \mathrm{CH}_{2}\right), 3.22-3.06(\mathrm{~m}$, $\left.2 \mathrm{H} ; \mathrm{CH}_{2}\right), 3.66-3.56\left(\mathrm{~m}, 2 \mathrm{H} ; \mathrm{CH}_{2}\right), 2.22-2.08\left(\mathrm{~m}, 2 \mathrm{H} ; \mathrm{CH}_{2}\right), 1.94-1.82\left(\mathrm{~m}, 2 \mathrm{H} ; \mathrm{CH}_{2}\right)$, $1.22 \mathrm{ppm}\left(\mathrm{s}, 3 \mathrm{H} ; \mathrm{CH}_{3}\right), 1.12\left(\mathrm{~s}, 3 \mathrm{H} ; \mathrm{CH}_{3}\right) ;{ }^{13} \mathrm{C} \mathrm{NMR}\left(100.6 \mathrm{MHz}, \mathrm{CDCl}_{3}, 25^{\circ} \mathrm{C}\right) \delta=$ $172.7,165.3,164.8,159.8,150.0,147.1,140.9$, 135.9, 134.3, 131.9, 130.0, 128.2, 
$128.0,127.5,125.9,125.0,122.8,122.7,122.1,121.7,120.0,119.6,118.6,115.6$, 111.2, 109.6, 107.0, 106.9, 52.9, 43.3, 40.2, 39.3, 33.9, 26.1, 24.8, 20.0 ppm; HRMS (TOF, EI+): $m / z$ : calcd for $\mathrm{C}_{36} \mathrm{H}_{33} \mathrm{~N}_{5} \mathrm{O}_{6}: 631.2431$; found: 631.2422 .

\section{Acknowledgements}

The financial support by the Ministerio de Ciencia e Innovación, Madrid (grant CTQ2008-06777-C02-02/BQU, PhD fellowship for P.R.), the Consejería de Economía, Innovación y Ciencia, Seville (grant P08-FQM-3685), the Swedish Research Council (grant 622-2010-280), the European Research Council (ERC FP7/2007-2013 No. 203952), the Research Foundations of Carl Trygger and Kristina Stenborg, and the Swedish Foundation for International Cooperation in Research and Higher Education (STINT) is gratefully acknowledged. 


\section{References}

[1] A. P. de Silva, S. Uchiyama, Nature Nanotechnol. 2007, 2, 399-410.

[2] K. Szaciłowski, Chem. Rev. 2008, 108, 3481-3548.

[3] J. Andréasson, U. Pischel, Chem. Soc. Rev. 2010, 39, 174-188.

[4] U. Pischel, Aust. J. Chem. 2010, 63, 148-164.

[5] A. Credi, Angew. Chem. 2007, 119, 5568-5572; Angew. Chem. Int. Ed. 2007, 46, 5472-5475.

[6] S. Angelos, Y.-W. Yang, N. M. Khashab, J. F. Stoddart, J. I. Zink, J. Am. Chem. Soc. 2009, 131, 11344-11346.

[7] R. J. Amir, M. Popkov, R. A. Lerner, C. F. Barbas III, D. Shabat, Angew. Chem. 2005, 117, 4452-4455; Angew. Chem. Int. Ed. 2005, 44, 4378-4381.

[8] S. Ozlem, E. U. Akkaya, J. Am. Chem. Soc. 2009, 131, 48-49.

[9] A. P. de Silva, M. R. James, B. O. F. McKinney, D. A. Pears, S. M. Weir, Nature Mater. 2006, 5, 787-790.

[10] D. C. Magri, G. J. Brown, G. D. McClean, A. P. de Silva, J. Am. Chem. Soc. 2006, $128,4950-4951$.

[11] D. Margulies, A. D. Hamilton, J. Am. Chem. Soc. 2009, 131, 9142-9143.

[12] T. Konry, D. R. Walt, J. Am. Chem. Soc. 2009, 131, 13232-13233.

[13] O. A. Bozdemir, R. Guliyev, O. Buyukcakir, S. Selcuk, S. Kolemen, G. Gulseren, T. Nalbantoglu, H. Boyaci, E. U. Akkaya, J. Am. Chem. Soc. 2010, 132, 8029-8036.

[14] F. M. Raymo, M. Tomasulo, Chem. Soc. Rev. 2005, 34, 327-336.

[15] F. M. Raymo, M. Tomasulo, J. Phys. Chem. A 2005, 109, 7343-7352.

[16] S. L. Gilat, S. H. Kawai, J. M. Lehn, Chem. Eur. J. 1995, 1, 275-284.

[17] A. Fernández-Acebes, J.-M. Lehn, Chem. Eur. J. 1999, 5, 3285-3292.

[18] M. Irie, Chem. Rev. 2000, 100, 1685-1716.

[19] T. B. Norsten, N. R. Branda, Adv. Mater. 2001, 13, 347-349.

[20] A. J. Myles, N. R. Branda, Adv. Funct. Mater. 2002, 12, 167-173.

[21] T. Fukaminato, T. Sasaki, T. Kawai, N. Tamai, M. Irie, J. Am. Chem. Soc. 2004, $126,14843-14849$.

[22] M. Berberich, A.-M. Krause, M. Orlandi, F. Scandola, F. Würthner, Angew. Chem. 2008, 120, 6718-6721; Angew. Chem. Int. Ed. 2008, 47, 6616-6619.

[23] J. Kärnbratt, M. Hammarson, S. Li, H. L. Anderson, B. Albinsson, J. Andréasson, Angew. Chem. 2010, 122, 1898-1901; Angew. Chem. Int. Ed. 2010, 49, 1854-1857.

[24] J. Andréasson, S. D. Straight, S. Bandyopadhyay, R. H. Mitchell, T. A. Moore, A.

L. Moore, D. Gust, Angew. Chem. 2007, 119, 976-979; Angew. Chem. Int. Ed. 2007, 46, 958-961.

[25] J. Andréasson, S. D. Straight, S. Bandyopadhyay, R. H. Mitchell, T. A. Moore, A. L. Moore, D. Gust, J. Phys. Chem. C 2007, 111, 14274-14278.

[26] J. Andréasson, S. D. Straight, T. A. Moore, A. L. Moore, D. Gust, J. Am. Chem. Soc. 2008, 130, 11122-11128.

[27] J. Andréasson, G. Kodis, Y. Terazono, P. A. Liddell, S. Bandyopadhyay, R. H. Mitchell, T. A. Moore, A. L. Moore, D. Gust, J. Am. Chem. Soc. 2004, 126, 1592615927.

[28] J. Andréasson, S. D. Straight, G. Kodis, C.-D. Park, M. Hambourger, M. Gervaldo, B. Albinsson, T. A. Moore, A. L. Moore, D. Gust, J. Am. Chem. Soc. 2006, 128, 1625916265.

[29] J. Andréasson, S. D. Straight, T. A. Moore, A. L. Moore, D. Gust, Chem. Eur. J. 2009, 15, 3936-3939.

[30] J. L. Bahr, G. Kodis, L. de la Garza, S. Lin, A. L. Moore, T. A. Moore, D. Gust, J. Am. Chem. Soc. 2001, 123, 7124-7133. 
[31] M. Tomasulo, E. Deniz, R. J. Alvarado, F. M. Raymo, J. Phys. Chem. C 2008, 112, 8038-8045.

[32] L. Y. Zhu, W. W. Wu, M. Q. Zhu, J. J. Han, J. K. Hurst, A. D. Q. Li, J. Am. Chem. Soc. 2007, 129, 3524-3526.

[33] S. Mao, R. K. P. Benninger, Y. L. Yan, C. Petchprayoon, D. Jackson, C. J. Easley, D. W. Piston, G. Marriott, Biophys. J. 2008, 94, 4515-4524.

[34] Z. Guo, W. Zhu, L. Shen, H. Tian, Angew. Chem. 2007, 119, 5645-5649; Angew. Chem. Int. Ed. 2007, 46, 5549-5553.

[35] D. Margulies, C. E. Felder, G. Melman, A. Shanzer, J. Am. Chem. Soc. 2007, 129, 347-354.

[36] W. Sun, C. Zhou, C.-H. Xu, C.-J. Fang, C. Zhang, Z.-X. Li, C.-H. Yan, Chem. Eur. J. 2008, 14, 6342-6351.

[37] M. Suresh, A. Ghosh, A. Das, Chem. Commun. 2008, 3906-3908.

[38] S. Kumar, V. Luxami, R. Saini, D. Kaur, Chem. Commun. 2009, 3044-3046.

[39] P. Remón, R. Ferreira, J.-M. Montenegro, R. Suau, E. Pérez-Inestrosa, U. Pischel, ChemPhysChem 2009, 10, 2004-2007.

[40] M. Semeraro, A. Credi, J. Phys. Chem. C 2010, 114, 3209-3214.

[41] A. A. García, S. Cherian, J. Park, D. Gust, F. Jahnke, R. Rosario, J. Phys. Chem. A 2000, 104, 6103-6107.

[42] A. García, M. Marquéz, T. Cai, R. Rosario, Z. Hu, D. Gust, M. Hayes, S. A. Vail, C.-D. Park, Langmuir 2007, 23, 224-229.

[43] The following electrochemical (all vs. SCE in polar solvents) and spectroscopic data were used for the calculation of the free energy changes for oxidative and reductive electron transfer in the dyads: a) spiropyran: $E_{\mathrm{ox}}=1.20 \mathrm{~V}, E_{\mathrm{red}}=-1.25 \mathrm{~V}$ (both in benzonitrile, ref. 41); b) aminonaphthalimide: $E_{\mathrm{ox}}=1.20 \mathrm{~V}, E_{\mathrm{red}}=-1.41 \mathrm{~V}$ (both in butyronitrile, ref. 44), $E^{*}=2.7 \mathrm{eV}$ (determined for 2-M according to ref. 44); c) dansyl: $E_{\mathrm{ox}}=0.9 \mathrm{~V}, E_{\mathrm{red}}=-2.02 \mathrm{~V}$ (both in acetonitrile, ref. 45 ), $E^{*}=3.0 \mathrm{eV}$ (determined for 3$\mathbf{M}$ according to ref. 44); d) perylene: $E_{\mathrm{ox}}=0.85 \mathrm{~V}$ (in acetonitrile, ref. 46 ), $E_{\text {red }}=-1.67$ $\mathrm{V}$ (in $N, N$-dimethylformamide, ref. 46), $E^{*}=2.8 \mathrm{eV}$ (determined for 4-M from the intersection of the normalized absorption and emission spectra). The redox potentials refer to closely related model compounds as used in the cited references. The Coulomb term $C$ was taken as $-0.06 \mathrm{eV}$ in acetonitrile.

[44] S. R. Greenfield, W. A. Svec, D. Gosztola, M. R. Wasielewski, J. Am. Chem. Soc. 1996, 118, 6767-6777.

[45] P. Ceroni, I. Laghi, M. Maestri, V. Balzani, S. Gestermann, M. Gorka, F. Vögtle, New J. Chem. 2002, 26, 66-75.

[46] M. Montalti, A. Credi, L. Prodi, M. T. Gandolfi, Handbook of Photochemistry, CRC Press, Francis and Taylor Group, Boca Raton, 2006.

[47] A. P. de Silva, H. Q. N. Gunaratne, J.-L. Habib-Jiwan, C. P. McCoy, T. E. Rice, J.P. Soumillion, Angew. Chem. 1995, 107, 1889-1891; Angew. Chem. Int. Ed. Engl. 1995, 34, 1728-1731.

[48] Y. Q. Gao, R. A. Marcus, J. Phys. Chem. A 2002, 106, 1956-1960.

[49] G. de Ruiter, E. Tartakovsky, N. Oded, M. E. van der Boom, Angew. Chem. 2010, 122, 173-176; Angew. Chem. Int. Ed. 2010, 49, 169-172.

[50] U. Pischel, Angew. Chem. 2010, 122, 1396-1398; Angew. Chem. Int. Ed. 2010, 49, 1356-1358.

[51] U. Pischel, J. Andréasson, New J. Chem. 2010, 34, 2701-2703.

[52] F. M. Raymo, R. J. Alvarado, S. Giordani, M. A. Cejas, J. Am. Chem. Soc. 2003, 125, 2361-2364.

[53] F. M. Raymo, S. Giordani, Org. Lett. 2001, 3, 3475-3478. 
[54] F. M. Raymo, S. Giordani, Org. Lett. 2001, 3, 1833-1836.

[55] F. M. Raymo, S. Giordani, J. Am. Chem. Soc. 2002, 124, 2004-2007.

[56] F. M. Raymo, S. Giordani, Proc. Nat. Acad. Sci. 2002, 99, 4941-4944.

[57] S. Silvi, E. C. Constable, C. E. Housecroft, J. E. Beves, E. L. Dunphy, M.

Tomasulo, F. M. Raymo, A. Credi, Chem. Eur. J. 2009, 15, 178-185.

[58] K. Szaciłowski, Chem. Eur. J. 2004, 10, 2520-2528.

[59] H. T. Baytekin, E. U. Akkaya, Org. Lett. 2000, 2, 1725-1727.

[60] J. V. Morris, M. A. Mahaney, J. R. Huber, J. Phys. Chem. 1976, 80, 969-974.

[61] T. Stafforst, D. Hilvert, Chem. Commun. 2009, 287-288. 


\section{Schemes and Figure Legends}

Scheme 1. Structures of 1-SP, 1-MEH ${ }^{+}$, and 1-ME and their interconversion by photonic and/or chemical inputs.

Scheme 2. a) Synthesis of 1-SP and its functionalization with fluorophores (2-SP, 3SP, 4-SP) and b) preparation of fluorophore model compounds (2-M, 3-M, 4-M).

Scheme 3. Switching of 2-MEH (initial state) by sequential application of inputs $I n_{l}$ and $\operatorname{In}_{2}$. Reversible logic by combinational switching of $\mathbf{2}-\mathbf{M E H}^{+}$(initial state) by application of $I n_{1}$ and $I n_{3}$ and of $\mathbf{5} \mathbf{H}^{+}$by application of $I n_{1}$.

Scheme 4. Representation of the logic circuit corresponding to the logically reversible switching of the combination $\mathbf{2}-\mathbf{M E H}^{+} / \mathbf{5}-\mathbf{H}^{+}$by $\operatorname{In}_{1}$ and $I n_{3}$.

Figure 1. Absorption spectra of 1-SP (dotted line), 1-MEH ${ }^{+}$(dashed line), and 1-ME (solid line) in acetonitrile.

Figure 2. Absorption spectra (three spectra on the left) of 2-M (solid line), 1-SP (dashed line), and 2-SP (dotted line) in acetonitrile. On the right the fluorescence spectra of optically matched solutions of 2-M (solid line) and 2-SP (dotted line) in acetonitrile are shown $\left(\lambda_{\mathrm{exc}}=417 \mathrm{~nm}\right)$.

Figure 3. Streak-camera fluorescence decays $\left(\lambda_{\mathrm{exc}}=398 \mathrm{~nm}\right.$; averaged for $\lambda_{\mathrm{obs}}=500$ $540 \mathrm{~nm}$ ) for 3-M (filled circles), 3-SP (filled squares), 3-ME (empty squares) and 3$\mathbf{M E H}^{+}$(empty circles). The solid lines are to guide the eye, but do not correspond to the actual fits. Note that the model 3-M shows essentially no decay on the considered time scale. The decay curve of 3-ME contains still considerable contributions from the closed 3-SP (photostationary state). The decay of 3-MEH ${ }^{+}$contains a higher fraction of the short-lived component compared to 3-ME. This is likely the result of the suppression of thermal closing of $\mathbf{3}-\mathbf{M E H}^{+}$during the course of the measurement.

Figure 4. Sequential logic with $\mathbf{2 - \mathbf { M E H }}{ }^{+}$as initial state and $\operatorname{In}_{l}$ (phosphazene base) and $I n_{2}$ (irradiation at $\lambda>530 \mathrm{~nm}$ ) as inputs. The horizontal line shows the threshold. Fluorescence signals above the threshold are considered as binary 1 and below as binary 0.

Figure 5. Repeated switching cycles of 2-SP. The application order of UV light (302 $\mathrm{nm})$, acid (TFA), base $\left(\mathrm{P}_{2}-\mathrm{Et}\right)$, and light of $\lambda>530 \mathrm{~nm}$ is shown for the first cycle and identical for the following cycles.

Figure 6. Fluorescence spectra $\left(\lambda_{\mathrm{exc}}=375 \mathrm{~nm}\right)$ of $\mathbf{5} \mathbf{H}^{+}$(left) and $\mathbf{2}-\mathbf{M E H}{ }^{+}$(right) upon addition of base $\left(I n_{1}\right)$ and irradiation at $\lambda>420 \mathrm{~nm}\left(I n_{3}\right)$. The input which actually leads to effective fluorescence switching is indicated for each system. The other input for the respective system $\left(\mathrm{In}_{3}\right.$ for $\mathbf{5} \mathbf{H}^{+}$and $I n_{1}$ for $\left.\mathbf{2}-\mathbf{M E H}{ }^{+}\right)$does not change the fluorescence. 
Table 1. Photophysical properties of model compounds and dyads.

\begin{tabular}{|c|c|c|c|c|c|c|c|c|c|}
\hline & $\begin{array}{l}\lambda_{\text {abs, } \max } / \mathrm{nm} \\
\left(\varepsilon / \mathrm{M}^{-1} \mathrm{~cm}^{-1}\right)\end{array}$ & $\lambda_{\mathrm{f}, \max } / \mathrm{nm}$ & $\Phi_{\mathrm{f}}^{[\mathrm{a}]}$ & $\tau_{\mathrm{f}}^{[\mathrm{b}]}$ & $\Phi_{\mathrm{PET}}^{[\mathrm{c}]}$ & $\begin{array}{c}\mathrm{PSS}^{[\mathrm{d}]} \\
(\% \mathrm{SP} / \% \mathrm{ME})\end{array}$ & $\begin{array}{c}Q(\%)^{[\mathrm{e}]} \\
(\mathrm{SP} \rightarrow \mathrm{ME} / \\
\left.\mathrm{MEH}^{+}\right)\end{array}$ & $\begin{array}{l}R_{0} l \\
\AA^{[\mathrm{f}\rfloor}\end{array}$ & $\begin{array}{c}\Phi_{\mathrm{EET}}{ }^{[\mathrm{g}]} \\
\text { (Förster) }\end{array}$ \\
\hline 2-M & $416(10400)$ & 512 & 0.44 & $10.6 \mathrm{~ns}$ & & & & & \\
\hline 2-SP & $416(11000)$ & 512 & 0.056 & $1.40 \mathrm{~ns}$ & 0.87 & 55 & & 0 & \\
\hline 2-ME & [h] & [i] & $0.035^{[\mathrm{j}]}$ & $13 \mathrm{ps}$ & & 45 & 38 & 47 & 1.0 \\
\hline 2-MEH ${ }^{+}$ & [h] & [i] & $0.035^{[j]}$ & $15 \mathrm{ps}$ & & & 38 & 20 & 0.85 \\
\hline 3-M & $338(4600)$ & 518 & 0.25 & $12.6 \mathrm{~ns}$ & & & & & \\
\hline 3-SP & $341(11000)$ & 518 & 0.015 & $925 \mathrm{ps}$ & 0.94 & 54 & & 0 & \\
\hline 3-ME & [h] & [i] & $0.008^{[j]}$ & $8 \mathrm{ps}$ & & 46 & 44 & 43 & 1.0 \\
\hline 3-MEH ${ }^{+}$ & [h] & [i] & $0.008^{[j]}$ & $9 \mathrm{ps}$ & & & 44 & 19 & 0.80 \\
\hline 4-M & $439(33600)$ & 446 & 0.76 & $4.0 \mathrm{~ns}$ & & & & & \\
\hline 4-SP & 439 (32100) & 447 & 0.079 & $560 \mathrm{ps}$ & 0.90 & 58 & & 0 & \\
\hline 4-ME & [h] & [i] & $0.034^{[j]}$ & $16 \mathrm{ps}$ & & 42 & 57 & 38 & 1.0 \\
\hline 4-MEH ${ }^{+}$ & [h] & [i] & $0.034^{[j]}$ & $16 \mathrm{ps}$ & & & 57 & 35 & 0.99 \\
\hline
\end{tabular}

[a] Fluorescence quantum yields of the model compounds measured with quinine sulfate in $0.05 \mathrm{M}$ $\mathrm{H}_{2} \mathrm{SO}_{4}$ as standard $\left(\Phi_{\mathrm{f}}=0.55\right), 20 \%$ error. The values of the SP dyads are determined relative to the ones of the models. [b] Fluorescence lifetimes, 10\% error. [c] Quantum yields for PET, calculated with equation 2. [d] Distribution of spiropyran and merocyanine isomers in the PSS $(\lambda=302 \mathrm{~nm})$. [e] Fluorescence quenching observed for the PSS. [f] Critical radius of electronic energy transfer (Förster mechanism), calculated with equation 3. [g] Quantum yields for electronic energy transfer estimated from the Förster formulation, assuming a distance of $15 \AA$ between fluorophore and photochrome. [h] The long-wavelength absorption maxima of the protonated merocyanine $\left(\mathrm{MEH}^{+}\right)$and the merocyanine (ME) forms of the dyad are determined by photochrome part (see text for data for the model compounds 1-MEH ${ }^{+}$and 1-ME). [i] The fluorescence maximum remains unaltered with respect to the fluorescence observed for the SP form of the corresponding dyad. [j] Apparent fluorescence quantum yield, determined from the fluorescence quenching in the PSS (irradiation of the SP form with $302 \mathrm{~nm}$ light) and subsequent addition of 1 equiv TFA (for the $\mathrm{MEH}^{+}$form). 
Table 2. Truth table of the reversible logic gate $\mathbf{5} \mathbf{H}^{+} / \mathbf{2}-\mathbf{M E H} \mathbf{H}^{+}$.

\begin{tabular}{cccc}
\hline$I n_{1}{ }^{[\mathrm{a}]}$ & $\operatorname{In}_{3}{ }^{[\mathrm{b}]}$ & $O_{1}{ }^{[\mathrm{c}]}\left(I_{\mathrm{f}, \mathrm{rel}}\right)$ & $O_{2}{ }^{[\mathrm{d}]}\left(I_{\mathrm{f}, \mathrm{rel}}\right)$ \\
\hline 0 & 0 & $0(0.62)$ & $1(0.99)$ \\
1 & 0 & $0(0.64)$ & $0(0.03)$ \\
0 & 1 & $1(1.00)$ & $1(1.00)$ \\
1 & 1 & $1(1.00)$ & $0(0.03)$ \\
\hline
\end{tabular}

[a] 1 equiv $\mathrm{P}_{2}$-Et. [b] $\lambda>420 \mathrm{~nm}, 210 \mathrm{~s}$. [c] Aminonaphthalimide fluorescence, $\lambda_{\text {obs }}=512 \mathrm{~nm}$; threshold $I_{\mathrm{f}, \text { rel }}=0.7$. [d] Anthracene fluorescence, $\lambda_{\mathrm{obs}}=416 \mathrm{~nm}$; threshold $I_{\mathrm{f}, \text { rel }}=0.7$. 


\section{Text for Table of Contents}

In order to switch: Molecular switches in form of spiropyran (SP)-spacer-fluorophore (F) dyads have been used to implement sequential logic (2-input priority AND gate) and reversible logic. The dyads have been designed to yield well-predictable fluorescence responses by modulation of electronic energy transfer. In this way switches were obtained, which can be conveniently operated, recycled and reset through photochromic processes and acid-base chemistry. 


\section{Keywords}

spiropyran $\bullet$ photochromism $\bullet$ energy transfer $\bullet$ switches $\bullet$ logic gates 